\title{
Risk factors for severity of thrombocytopenia in full term infants: a single center study
}

\author{
Amira M. Saber ${ }^{1}$, Shereen P. Aziz², Al Zahraa E. Almasry ${ }^{1}$ and Ramadan A. Mahmoud ${ }^{1 *}$ (B)
}

\begin{abstract}
Background: Neonatal thrombocytopenia (NT) (platelet count $<150 \times 10^{9} / \mathrm{L}$ ) is a common finding in the neonatal intensive care unit (NICU). The main aim of this study was to assess the prevalence, risk factors, and outcomes of severe NT in full term (FT) infants.
\end{abstract}

Methods: During the study period, all FT infants who met the inclusion criteria for NT on two occasions were included. Maternal data, such as maternal age, weight, gestational age, mode of delivery, and history of systemic diseases, including diabetes mellitus, pre-eclampsia, systemic lupus erythematosus, and immune thrombocytopenic purpura, were recorded. Furthermore, neonatal data, such as gender, neonatal weight, causes/duration of admission, types of respiratory support used, complete blood count measurements, and outcomes for neonates admitted to the NICU, were recorded.

Results: In total, 55 FT infants with NT met the inclusion criteria, and 29 (52.73\%) cases had severe NT. The most common cause of NT was neonatal sepsis (20 cases, 36.35\%), followed by a postoperative state (5 cases, 9.09\%). Moreover, in cases of positive blood cultures, the most commonly isolated organism was Escherichia coli (6 cases, 10.90\%), followed by Klebsiella (5 cases, 9.09\%). Cases of severe NT needed more platelet transfusions $(P=0.001)$ and had higher rates of mortality $(P=0.001)$ when compared to cases of mild/moderate NT associated with signs of bleeding and pulmonary/intraventricular hemorrhage (IVH) $(P=0.001)$.

Conclusion: Severe NT compared to mild/moderate NT, associated with signs of bleeding and pulmonary/IVH, needed more platelet transfusions, and had increased mortality. Further research is needed to explain which of these complications related to severity of thrombocytopenia or were associated with original disease of the babies.

Keywords: Neonatal thrombocytopenia, Full term infant, Rick factors, Outcome

\section{Introduction}

Thrombocytopenia, generally defined as a platelet count $<150 \times 10^{9} / \mathrm{L}$, affects up to $35 \%$ of all patients admitted to the neonatal intensive care unit (NICU) $[1,2]$. Early onset neonatal thrombocytopenia (NT), presenting in the first $72 \mathrm{~h}$ of life, is commonly associated with

\footnotetext{
* Correspondence: ramadan.aboelhassan@yahoo.com;

ramadan_aboelhassan@med.sohag.edu.eg

'Department of Pediatrics, Faculty of Medicine, Sohag University, 15 University Street, Sohag 82524, Egypt

Full list of author information is available at the end of the article
}

pregnancy complications, such as intrauterine growth restriction, maternal diabetes, maternal immune thrombocytopenic purpura (ITP), congenital infection or neonatal alloimmune thrombocytopenia (NAT) [3]. While late onset NT, presenting after $72 \mathrm{~h}$ of life, is usually secondary to sepsis or necrotizing enterocolitis (NEC), it is usually more severe and prolonged [4].

There are two main underlying pathological mechanisms for NT: increased destruction/sequestration or decreased production of platelets. The underlying cause of

C C The Author(s). 2021 Open Access This article is licensed under a Creative Commons Attribution 4.0 International License, which permits use, sharing, adaptation, distribution and reproduction in any medium or format, as long as you give appropriate credit to the original author(s) and the source, provide a link to the Creative Commons licence, and indicate if changes were made. The images or other third party material in this article are included in the article's Creative Commons licence, unless indicated otherwise in a credit line to the material. If material is not included in the article's Creative Commons licence and your intended use is not permitted by statutory regulation or exceeds the permitted use, you will need to obtain permission directly from the copyright holder. To view a copy of this licence, visit http://creativecommons.org/licenses/by/4.0/ The Creative Commons Public Domain Dedication waiver (http://creativecommons.org/publicdomain/zero/1.0/) applies to the data made available in this article, unless otherwise stated in a credit line to the data. 
NT can often be predicted by the timing of the onset of the thrombocytopenia and its natural history [5]. However, from a clinical point of view, many cases have a compound etiology for thrombocytopenia.

In most cases, NT is mild to moderate and resolves without intervention. Life-threatening bleeding, intraventricular hemorrhage (IVH), or pulmonary hemorrhage with a high risk of neurodevelopmental impairment may occur in severe NT [6, 7]. However, NT occurs less frequency in full term (FT) infants than in preterm infants, as demonstrated in one cohort study where it was $2 \%$ [8]. Moreover, the main risk factors in FT infants were occult infection, placental insufficiency, and NAT, which differs from preterm risk factors, such as sepsis, TORCH infection, and NEC [9].

Furthermore, the outcome of NT depends on several factors, such as birth weight, gestational age, platelet count and underlying cause [10]. The relationship between risk factors for NT and degree of severity in FT infants have only been researched in some studies $[9,11,12]$; however, there were no clear associations between risk factor and severity. Moreover, a clear correlation between the degree of NT and resulting bleeding risk factors has not been demonstrated [12]. Therefore, the aim of this study is to determine the risk factors and outcomes of severe NT in FT infants.

\section{Methods}

The current clinical study was performed at the NICU in the Pediatrics Department, in cooperation with the Department of Clinical Pathology, at our University, during the period from January 2019 to the end of December 2019. Our NICU was a tertiary care level 30 beds, with 10 beds level 3, with about 1000 neonatal admission/year. Local ethical approval for the study was obtained from our Research Committee of the Faculty of Medicine (Number 652, 2018), and written informed consent was obtained from all parents of the participating children.

\section{Patient selection}

All FT infants with a diagnosis of NT on two occasions, at the time of study, were included in the study, whether thrombocytopenia was discovered within the first complete blood count $(\mathrm{CBC})$ or later. Exclusion criteria included any preterm delivery $<37$ weeks gestational age or neonates who had multiple congenital malformations at birth. The severity of NT was determined according to Roberts et al. [4] and categorized into mild thrombocytopenia (platelet count 100-150 $\times 10^{9} / \mathrm{L}$ ), moderate thrombocytopenia $\left(50-99 \times 10^{9} / \mathrm{L}\right)$, and severe thrombocytopenia $\left(<50 \times 10^{9} / \mathrm{L}\right)$. Furthermore, cases were classified as early onset NT (presenting in the first $72 \mathrm{~h}$ of life) and late onset NT (presenting after $72 \mathrm{~h}$ of life). We used the following restricted guidelines for administering platelet transfusions in our unit: (I) platelet count $\leq 100 \times 10^{9} / \mathrm{L}$ just going to or just having had surgery, or having clinical bleeding, (II) platelet count $\leq 50 \times 10^{9} / \mathrm{L}$ and unstable (mechanical ventilation or vasopressors), and (III) platelet count of $20 \times 10^{9} / \mathrm{L}$ and stable $[6,11]$.

\section{Maternal data collection}

Fifty-five FT infants met the inclusion criteria and were enrolled in the study. Maternal data such as maternal age, weight, gestational age, mode of delivery, and maternal diseases, including diabetes mellitus, preeclampsia, premature rupture of membranes (PROM), systemic lupus erythematosus, ITP, and positive consanguinity, were recorded.

\section{Neonatal data collection and investigations}

Neonatal data, such as gender, neonatal weight, APGAR score, causes of admission to NICU, duration of admission in NICU, types of respiratory support used, CBC measurements (done by Cell Dyn 3700, automated cell counter, Abbott Diagnostics, USA), and thrombocytopenic manifestations, such as purpura, ecchymosis, gastric bleeding, bleeding from puncture site, and pulmonary hemorrhage or IVH, were recorded. Detailed systemic examinations focusing on skin examination, macrosomia, head circumference, intrauterine growth retardation, congenital anomalies, and dysmorphic features were recorded. Septic work-ups and blood cultures/sensitivities were performed for all included cases. A TORCH screen was carried out (by ARCHITECT i1000SR, Abbott Diagnostics, USA) in cases of suspected congenital infection. Chromosomal assays [13, 14] were performed in cases of suspected chromosomal abnormities. Neonates suspected of having NAT, based on the presentation and clinic course of the illness, were designated as having an idiopathic cause as the diagnostic test for NAT is not available in our laboratory. Thrombocytopenia related morbidity were recorded in terms of pulmonary/IVH and mortality (alive or dead) for the study group.

\section{Statistical analysis}

Data was analyzed using STATA version 14.2 (Stata Statistical Software: Release 14.2, College Station, TX: Stata Corp LP). Quantitative data was represented as mean and standard deviation, and median and range. Data was analyzed using Student's t-test to compare the means of two groups. When the data was not normally distributed, the Mann-Whitney test was used. Qualitative data was presented as number and percentage and was compared using either the Chi square test or Fisher 
exact test. The $P$ value was considered significant if it was $<0.05$.

\section{Results}

\section{Patient characteristics}

In total, 55 FT infants who met the inclusion criteria were included in this study. Thirty $(54.55 \%)$ cases were delivered by Caesarean section and 25 (45.45\%) cases by normal vaginal delivery. Of these, 33 (60.00\%) were male and $22(40.00 \%)$ female. The mean \pm SD of the platelet count at diagnosis was $67.53 \pm 46.91 \times 10^{9} / \mathrm{L}$. In this study, $29(52.73 \%)$ cases had severe NT at diagnosis and $26(47.27 \%)$ cases had mild/moderate NT. Other maternal and neonatal characteristics are described in Table 1.

\section{Causes of neonatal thrombocytopenia}

As shown in Table 2, the most common cause of NT was neonatal sepsis (20 cases, 36.35\%), postoperative state (5 cases, 9.09\%) and idiopathic cases in (5 cases, 9.09\%). Chromosomal assays were carried out for 6

Table 1 Maternal and neonatal characteristics of studied population

\begin{tabular}{ll}
\hline Variables & Summary statistics \\
\hline Mother's age/years (mean \pm SD) & $29.18 \pm 4.33$ \\
Mother's weight/kg (mean \pm SD) & $77.36 \pm 6.31$ \\
Positive consanguinity & $13(23.64 \%)$ \\
Mothers had Diabetes & $9(16.36 \%)$ \\
Mothers had Preeclampsia & $6(10.91 \%)$ \\
History of PROM & $3(5.45 \%)$ \\
Mode of delivery & \\
Normal vaginal delivery & $25(45.45 \%)$ \\
Cesarean section & $30(54.55 \%)$ \\
Neonatal Weight (Kg) (mean \pm SD) & $2.77 \pm 0.61$ \\
Gender (Male/female) & $33(60.00 \%) / 22(40.00)$ \\
Neonatal WBCs (mean \pm SD) & $13.57 \pm 4.83$ \\
Neonatal Hemoglobin (mean \pm SD) & $15.86 \pm 4.46$ \\
Neonatal Platelet count at diagnosis (mean \pm SD) & $67.53 \pm 46.91$ \\
Thrombocytopenia degree at diagnosis & $29(52.73 \%)$ \\
Mild & $2(3.64 \%)$ \\
Moderate & $19(34.55 \%)$ \\
Severe & $7(12.73 \%)$ \\
Manifestation of thrombocytopenia & $25.45 \%)$ \\
\hline
\end{tabular}

Table 2 Distribution of studied population according to some different variables

\begin{tabular}{|c|c|}
\hline Variables & Summary (total 55 cases) \\
\hline \multicolumn{2}{|l|}{ Diagnosis of thrombocytopenia } \\
\hline Late onset sepsis & $13(23.63 \%)$ \\
\hline Early onset sepsis & $7(12.72 \%)$ \\
\hline Post-surgery & $5(9.09 \%)$ \\
\hline IUGR and placental insufficiency & $4(7.27 \%)$ \\
\hline Disseminated intravascular coagulopathy & $3(5.45 \%)$ \\
\hline Maternal ITP & $3(5.45 \%)$ \\
\hline DM, hypoglycemia & $3(5.45 \%)$ \\
\hline Down syndrome & $2(3.63 \%)$ \\
\hline SLE & $2(3.63 \%)$ \\
\hline Post exchange transfusion & $2(3.63 \%)$ \\
\hline Tetralogy of Fallot & $2(3.63 \%)$ \\
\hline Birth asphyxia & $2(3.63 \%)$ \\
\hline Metabolic disorders & $2(3.63 \%)$ \\
\hline Idiopathic & $5(9.09 \%)$ \\
\hline \multicolumn{2}{|l|}{ Onset of thrombocytopenia } \\
\hline Early onset thrombocytopenia & $18(32.72 \%)$ \\
\hline Late onset thrombocytopenia & $37(67.27)$ \\
\hline \multicolumn{2}{|l|}{ Severity of thrombocytopenia } \\
\hline Mild thrombocytopenia & $19(34.54 \%)$ \\
\hline Moderate thrombocytopenia & $7(12.72 \%)$ \\
\hline Severe thrombocytopenia & $29(52.73 \%)$ \\
\hline \multicolumn{2}{|l|}{ Blood culture } \\
\hline No gross & $35(63.64 \%)$ \\
\hline E-coli & $6(10.90 \%)$ \\
\hline Klebesiella & $5(9.09 \%)$ \\
\hline Enterobacter & $3(5.45 \%)$ \\
\hline Pneumococci & $3(5.45 \%)$ \\
\hline Staphylococcus aureus & $3(5.45 \%)$ \\
\hline \multicolumn{2}{|l|}{ Respiratory support } \\
\hline Room air & $15(27.27 \%)$ \\
\hline CPAP & $25(45.45 \%)$ \\
\hline Mechanical ventilation & $15(27.27 \%)$ \\
\hline Duration of hospital stay (mean \pm SD) & $8.67 \pm 3.95$ \\
\hline \multicolumn{2}{|l|}{ Outcome } \\
\hline Alive & $49(89.10 \%)$ \\
\hline Dead & $6(10.90 \%)$ \\
\hline
\end{tabular}

patients; 2 had Down syndrome (3.70\%). A TORCH screen was performed in 10 patients, and no cases had congenital infection. However, in cases of positive blood cultures, the most commonly isolated organism was Escherichia coli (6 cases, 10.90\%), followed by Klebsiella (5 cases, 9.09\%). Early onset NT was found in 18 
(32.72\%) cases, while late onset NT was found in 37 $(67.27 \%)$ cases.

\section{Risk factors for thrombocytopenia severity}

Classification of the degree of NT into mild, moderate, and severe showed that there were 19 (34.54\%), 7 (12.72\%) and 29 (52.73\%) cases, respectively.

As shown in Table 2, 35 (63.64\%) cases of NT needed respiratory support, either CPAP or mechanical ventilation, due to the presence of respiratory problems in addition to the NT. The total duration of hospital stay was $8.67 \pm 3.95$ days. Furthermore, in this study, 6 (10.90\%) cases were declared, 5 of whom had severe NT. However, there were no significant differences in severity of NT and in maternal risk factors, such as diabetes $(P=0.08)$, pre-eclampsia $(P=0.09)$, history of PROM $(P=0.62)$, and mode of delivery $(P=0.51)$. Furthermore, in this study, the presence or absence of neonatal sepsis did not increase the severity of NT $(P=0.13)$, as shown in Table 3.

\section{Thrombocytopenia manifestations}

With regard to the manifestations of NT in FT infants (Table 3), most mild and moderate cases were asymptomatic (25/26 cases, 96.15\%), and only one case had gastrointestinal bleeding. In contrast, 22/29 (75.86\%) cases who had severe NT were symptomatic from gastrointestinal bleeding, bleeding from puncture sites, or pulmonary/IVH $(P=0.001)$. One of the idiopathic cases had severe NT and develop IVH since birth. Moreover, FT infants with severe NT needed more platelet transfusions compared to cases who had mild/moderate NT $(P=0.001)$.

Thrombocytopenia related morbidity and mortality

As shown in Table 4, the need for invasive mechanical ventilation was associated with severe NT in 14/29

Table 3 Relation between thrombocytopenia severity and maternal/ neonatal characteristics

\begin{tabular}{|c|c|c|c|}
\hline \multirow[t]{2}{*}{ Variable } & \multicolumn{2}{|c|}{ Thrombocytopenia (total 55 cases) } & \multirow{2}{*}{$\begin{array}{l}P \\
\text { value }\end{array}$} \\
\hline & $\begin{array}{l}\text { Mild/moderate } \\
N=26(47.27 \%)\end{array}$ & $\begin{array}{l}\text { Severe } \\
N=29(52.73 \%)\end{array}$ & \\
\hline Mother's age/years (mean $\pm \mathrm{SD}$ ) & $29.69 \pm 4.77$ & $28.72 \pm 3.92$ & 0.41 \\
\hline Mother's weight/kg (mean \pm SD) & $77.56 \pm 5.67$ & $76.34 \pm 8.23$ & 0.62 \\
\hline Positive consanguinity & $6(23.08 \%)$ & $7(24.14 \%)$ & 0.93 \\
\hline Mothers had Diabetes & $5(19.23 \%)$ & $3(10.34 \%)$ & 0.08 \\
\hline Mothers had Preeclampsia & $5(19.23 \%)$ & $1(3.45 \%)$ & 0.09 \\
\hline History of PROM & $1(3.85 \%)$ & $2(6.90 \%)$ & 0.62 \\
\hline \multicolumn{4}{|l|}{ Mode of delivery } \\
\hline Normal vaginal delivery & $13(50.00 \%)$ & $12(41.38 \%)$ & \multirow[t]{2}{*}{0.51} \\
\hline Cesearn Section & $13(50.00 \%)$ & $17(58.62 \%)$ & \\
\hline Neonatal Weight/kg (mean \pm SD) & $2.77 \pm 0.74$ & $2.76 \pm 0.50$ & 0.97 \\
\hline Neonatal WBCs (Mean \pm SD) & $13.38 \pm 4.45$ & $13.74 \pm 5.22$ & 0.96 \\
\hline Neonatal Hemoglobin gram/dL (Mean \pm SD) & $15.99 \pm 3.19$ & $10.06 \pm 3.46$ & 0.001 \\
\hline \multicolumn{4}{|l|}{ Neonatal sepsis } \\
\hline No sepsis & $19(73.08 \%)$ & $16(55.17 \%)$ & \multirow[t]{3}{*}{0.13} \\
\hline Early onset sepsis & $4(15.38 \%)$ & $3(10.34 \%)$ & \\
\hline Late onset sepsis & $3(11.54 \%)$ & $10(34.48 \%)$ & \\
\hline \multicolumn{4}{|l|}{ Manifestation of thrombocytopenia } \\
\hline No & $25(96.15 \%)$ & $7(24.14 \%)$ & \\
\hline Bleeding from puncture site & 0 & $14(48.28 \%)$ & \multirow[t]{4}{*}{0.001} \\
\hline Gastrointestinal bleeding & $1(3.85 \%)$ & $4(13.79 \%)$ & \\
\hline Pulmonary hemorrhage & 0 & $2(6.90 \%)$ & \\
\hline Intraventricular hemorrhage & 0 & $2(6.90 \%)$ & \\
\hline \multicolumn{4}{|l|}{ Platelets transfusion } \\
\hline No & $26(100 \%)$ & $9(31.03 \%)$ & \multirow[t]{2}{*}{0.001} \\
\hline Yes & 0 & $20(68.97 \%)$ & \\
\hline
\end{tabular}


Table 4 Relationship between neonatal respiratory support, duration of hospital stay, outcome and degree of thrombocytopenia

\begin{tabular}{|c|c|c|c|}
\hline \multirow[t]{2}{*}{ Variable } & \multicolumn{2}{|c|}{ Thrombocytopenia (55cases) } & \multirow{2}{*}{$\begin{array}{l}P \\
\text { value }\end{array}$} \\
\hline & $\begin{array}{l}\text { Mild/moderate } \\
\mathrm{N}=26(47.27 \%)\end{array}$ & $\begin{array}{l}\text { Severe } \\
\mathrm{N}=29(52.73 \%)\end{array}$ & \\
\hline \multicolumn{4}{|l|}{ CPAP } \\
\hline No & $12(46.15 \%)$ & $18(62.07 \%)$ & \multirow[t]{2}{*}{0.23} \\
\hline Yes & $14(53.85 \%)$ & $11(37.93 \%)$ & \\
\hline \multicolumn{4}{|l|}{ Mechanical ventilation } \\
\hline No & $25(96.15 \%)$ & $15(51.72 \%)$ & \multirow[t]{2}{*}{0.001} \\
\hline Yes & $1(3.85 \%)$ & $14(48.28 \%)$ & \\
\hline \multicolumn{4}{|l|}{ Outcome } \\
\hline Alive & $25(96.15 \%)$ & $24(82.76 \%)$ & \multirow[t]{2}{*}{0.001} \\
\hline Dead & $1(3.85 \%)$ & $5(17.24 \%)$ & \\
\hline \multicolumn{4}{|l|}{ Duration of hospital stay (days) } \\
\hline Mean \pm SD & $9.19 \pm 3.70$ & $8.21 \pm 4.18$ & 0.21 \\
\hline Idiopathic thrombocytopenia (N) & $2 / 26(7.69 \%)$ & $3 / 29(10.34 \%)$ & 0.73 \\
\hline
\end{tabular}

(48.28\%) cases compared to only $1 / 26(3.85 \%)$ cases in those who had mild/moderate NT $(P=0.001)$. Furthermore, the neonatal mortality was high in cases with severe NT (5 cases out of a total 6 cases died) compared to only one case with mild/moderate NT who died ( $\mathrm{P}=$ 0.001).

\section{Discussion}

In this study, out of 55 FT infants who developed NT during the study period, about half of them had severe NT at diagnosis, and about two-thirds of cases appeared after $72 \mathrm{~h}$ of life. The most common causes of NT were neonatal sepsis and a postoperative state. Furthermore, when compared to mild/moderate NT, severe NT was associated with higher morbidity (pulmonary or IVH), needed more platelet transfusions, and had increased mortality.

In our study, severe NT was found in $52.73 \%$ of total thrombocytopenic cases. This result was higher than other studies. Gupta et al. [15] found that severe NT accounted for $34.4 \%$ of cases. In another study, $20 \%$ of cases were classified as severe NT [6]. However, in a large cohort study including 11,281 NICU admissions of term or preterm infants over 5 years, Roberts et al. [4] found that severe NT was only identified in $2.4 \%$ of cases. The reason for a higher incidence of NT in our study was probably because the incidence of sepsis in our group was high. As from the unpublished data the positive blood culture in our unit was reported in $36.6 \%$ of neonates admitted to NICU, with prevalence rate of about 6.6/1000 live births. Furthermore, the relationship between the increased severity of thrombocytopenia and rates of neonatal sepsis also shown in Charoo et al. [16]. In contrast to FT infants, in preterm babies, Christensen et al. [17] found that about $73 \%$ of extremely low birth weight infants, had at least a one-time platelet count < $150 \times 10^{9} / \mathrm{L}$ at some time during their NICU stay, and this incidence increased up to $85 \%$ among neonates with a birth weight $\leq 800 \mathrm{~g}$. Furthermore, in our study, most about two-thirds of NT cases in FT infants were late onset (after $72 \mathrm{~h}$ of life). This may also be due to the increased late onset sepsis in our study group. In contrast, in the Resch et al. [9] study, in which 76\% of cases were born preterm, early onset NT occurred in the majority of cases $(84.1 \%)$.

NT occurs more frequently in association with certain factors, such as sepsis, birth asphyxia, babies born to mothers with pre-eclampsia, and low birth weight. This was also seen in our study, where the most common cause of NT was neonatal sepsis, which occurred in about one-third of cases. Furthermore, the most commonly isolated organisms in septic neonates were gram negative (E. coli and Klebsiella) in $55 \%$ of cases. These results are in good agreement with Ree et al. [18], who found that severe NT occurred in $20 \%$ of septic neonates and the most commonly isolated organisms were gram negative. The pathogenesis of NT in neonatal sepsis is not completely understood. It has been suggested that endothelial damage activates reticuloendothelial removal of platelets in neonatal sepsis, and thrombocytopenia occurs as, ultimately, the rate of platelet production falls behind platelet consumption [2]. The second most common cause of NT in our study was a postoperative state. Although the definite causes of postoperative thrombocytopenia have not been established in the literature, many factors have been proposed, including post-transfusion dilution, infection-induced, drug-induced, heparin-induced, immune mediated, and others [19]. 
In NAT was an analogue of hemolytic disease of the newborn, thrombocytopenia results from transplacental passage of maternal antibodies to fetal platelets. Sensitization may occurs in the first pregnancy in about $50 \%$ of cases [4]. NAT is often associated with severe NT and may result in major bleeding, particularly IVH, which even occur intrauterine, as thrombocytopenia may occur early in pregnancy particularly in untreated women [20]. In this study, neonates suspected of having NAT were assigned as having an idiopathic thrombocytopenia as the diagnostic test for NAT is not available in our laboratory. We found no difference between NT severity and suspected NAT cases. This may be explained with the wide varieties of presentation of NAT [21].

In this study, most cases (58.18\%) were asymptomatic. The most common presentations, occurring mostly with severe NT, were cutaneous bleeding from previous puncture sites and gastrointestinal bleeding. These results agree with a study by Baer et al. [6] and also agree with Park et al. [22], who found that gastrointestinal hemorrhage in patients with aplastic anemia and severe thrombocytopenia was recorded in $5 \%$ of those for whom the lowest platelet count was $20 \times 10^{9} / \mathrm{L}$, compared with $1 \%$ of those for whom the lowest count was $20 \times 10^{9}-50 \times 10^{9} / \mathrm{L}$.

We found that pulmonary and IVH occurred exclusively with severe NT. This agrees with studies by Setzer et al. [23], and Bolat et al. [11] as they found that lower platelet counts correlated with a higher prevalence of IVH. Until now, it was unclear whether NT caused the IVH or whether it occurred afterwards, as a result of consumptive mechanisms. In contrast to our results, Baer et al. [6] found no relationship between the lowest platelet count recorded and the presence of pulmonary hemorrhage or IVH in patients with severe NT. They speculated that factors other than NT are prominent in the pathogenesis of those varieties of neonatal bleeding, such as coagulation disorders. Duppre et al. [24] found that a cellular and humoral coagulation disorder had more of a role in the occurrence of IVH in neonates than thrombocytopenia.

In our study, there were no statistically significant differences between duration of hospital stay and severity of NT. This may be explained by the increased mortality rate in severe NT group as the babies died early in the course of illness. These results did not agree with Resch et al. [9], who found the duration of stay to be positively related to the severity of NT and the number of subsequent platelet transfusions. Furthermore, in this study, half of the neonates with severe NT required mechanical ventilation, which may explain the bad general condition of these patients, and the actual morbidity and mortality may not only be related to severe NT but also to the original disease, such as sepsis, respiratory failure, shock, postoperative state, or disseminated intravascular coagulopathy.

The outcomes of NT in our study showed that mortality increased to $10.90 \%$ with severe NT. In a study by Resch et al. [9], a mortality rate of $10.8 \%$ was significantly associated with signs of bleeding $(P<0.05)$ and correlated with an increasing number of platelet transfusions $(\mathrm{P}<0.05)$, but not with the severity of NT $(P=0.4)$. Furthermore, results from studies by Baer et al. [6] and Resch et al. [9] found no relationship between the lowest platelet count recorded and the mortality rate; however, a direct relationship was observed between the number of platelet transfusions received and the mortality rate. In our study, two-thirds of cases with severe NT received at least once platelet transfusion, which may be explained by the fact that ill patients receive more platelet transfusions, or as adverse effects of platelet transfusions [25].

Our study has some limitations, mainly due to the single-center and short study time period. Nevertheless, during this one year study, 55 FT infants with NT were carefully analyzed, and cases were followed up until discharge or death; however, long term follow up may be needed in further researches. Moreover, it should be noted that diagnostic tests for NAT are not available in our lab; therefore, suspected cases were classed as idiopathic.

\section{Conclusion}

Thrombocytopenia is a frequent challenge between neonatologists. The most common causes of NT in FT infants were neonatal sepsis, a postoperative state and placental insufficiency. Furthermore, when severe NT compared to mild/moderate NT, associated with signs of bleeding and pulmonary/IVH, required more mechanical ventilation, needed more platelet transfusions, and had increased mortality. Further research is needed to explain which of these complications related to severity of thrombocytopenia or were associated with the bad general condition of these patients due to their original disease.

\section{Abbreviations \\ CBC: Complete blood count; FT: Full term; ITP: Immune thrombocytopenic purpura; IVH: Intraventricular hemorrhage; NAT: Neonatal alloimmune thrombocytopenia; NEC: Necrotizing enterocolitis; NICU: Neonatal intensive care unit; NT: Neonatal thrombocytopenia; PROM: Premature rupture of membranes.}

\section{Acknowledgements \\ The authors thank http://proof-reading-services.com for language editing.}

Authors' contributions

AMS, RAM are responsible for the study design, collection and interpretation of the data, manuscript writing. SPA performed laboratory investigations, participated drafting the manuscript. RAM, ZEA performed statistical analysis, 
ZEA revised the manuscript. All authors reviewed and approved the final manuscript for publication.

\section{Funding}

The authors received no funding to perform this study.

\section{Availability of data and materials}

The datasets used and/or analyzed during the current study are available from the corresponding author on reasonable request.

\section{Ethics approval and consent to participate}

The research related to human subject use complied with all the relevant national regulations and institutional policies. Local ethical approval for the study was obtained from the Research Committee of the Faculty of Medicine at Sohag University, Egypt (Number 652, 2018). Written informed consent was obtained from all parents of the participating children.

\section{Consent for publication}

The authors declare that they have obtained the consent for publication from each parent's patient.

\section{Competing interests}

The authors declare that they have no competing interests.

\section{Author details}

${ }^{1}$ Department of Pediatrics, Faculty of Medicine, Sohag University, 15 University Street, Sohag 82524, Egypt. ${ }^{2}$ Department of Clinical Pathology, Faculty of Medicine, Sohag University, Sohag, Egypt.

Received: 28 April 2020 Accepted: 4 January 2021

Published online: 12 January 2021

\section{References}

1. Chakravorty S, Roberts I. How I manage neonatal thrombocytopenia. Br J Haematol. 2012;156:155-62.

2. Sola-Visner M, Sallmon H, Brown R. New insights into the mechanisms of nonimmune thrombocytopenia in neonates. Semin Perinatol. 2009:33:4351.

3. Lyori H, Fujisawa K, Akatsuka J. Thrombocytopenia in neonates born to women with autoimmune thrombocytopenic purpura. Pediatr Hematol Oncol. 1997;14:367-73.

4. Roberts I, Murray N. Neonatal thrombocytopenia: causes and management. Arch Dis Child Fetal Neonatal Ed. 2003:88:F359-64.

5. Gunnink SF, Vlug R, Fijnvandraat K, Van Der Bom JG, Stanworth SJ, Lopriore E. Neonatal thrombocytopenia: etiology, management and outcome. Expert Rev Hematol. 2014;7:387-95.

6. Baer VL, Lambert DK, Henry E, et al. Severe thrombocytopenia in the NICU. Pediatrics. 2009;124:e1095-100.

7. Roberts IA, Murray NA. Thrombocytopenia in the newborn. Curr Opin Pediatr. 2003;15:17-23.

8. Sainio S, Jarvenpaa AL, Renlund M, Riikonen S, Teramo K, Kekomaki R. Thrombocytopenia in term infants: a population-based study. Obstet Gynecol. 2000;95:441-6.

9. Resch E, Hinkas O, Urlesberger B, Resch B. Neonata thrombocytopenia-causes and outcomes following platelet transfusions. Eur J Pediatr. 2018;177:1045-52.

10. Holzhauer S, Zieger B. Diagnosis and management of neonatal thrombocytopenia. Semin Fetal Neonat M. 2011:16:305-10.

11. Bolat F, Kilic SC, Oflaz MB, et al. The prevalence and outcomes of thrombocytopenia in a neonatal intensive care unit: a three-year report. Pediatr Hematol Oncol. 2012;29:710-20.

12. Sola MC. Evaluation and treatment of severe and prolonged thrombocytopenia in neonates. Clin Perinatol. 2004;31:1-14.

13. Jordan MJ, Simons A, Schmid M. Recommendations of the international standing committee on human cytogenetic nomenclature including new sequence-based cytogenomic nomenclature. Karger; 2016.

14. Bangs CD, Donlon TA. Metaphase chromosome preparation from culturedperipheral blood cells. Curr Protoc Hum Genet. 2005;4:4.1.

15. Gupta A, Mathai SS, Kanitkar M. Incidence of thrombocytopenia in the neonatal intensive care unit. Med J Armed Forces India. 2011;67:234-6.
16. Charoo BA, lqbal Jl, lqbal Q, Mushtaq S, Bhat AW, Nawaz I. Nosocomial sepsis-induced late onset thrombocytopenia in a neonatal tertiary care unit: a prospective study. Hematol Oncol Stem Cell Ther. 2009;2:349-53.

17. Christensen R, Henry E, Wiedmeier S, et al. Thrombocytopenia among extremely low birth weight neonates: data from a multihospital healthcare system. J Perinatol. 2006;26:348-53.

18. Ree IMC, Fustolo-Gunnink SF, Bekker V, Fijnvandraat KJ, Steggerda SJ, Lopriore E. Thrombocytopenia in neonatal sepsis: incidence, severity and risk factors. PLoS One. 2017;12:e0185581.

19. Chang JC. Postoperative thrombocytopenia: with etiologic, diagnostic, and therapeutic consideration. Am J Med Sci. 1996:311:96-105.

20. Giovangrandi Y, Daffos F, Kaplan C, Forestier F, Mac Aleese J, Moirot M. Very early intracranial haemorrhage in alloimmune fetal thrombocytopenia. Lancet. 1990;336(8710):310.

21. Arneth B. Neonatal immune incompatibilities between newborn and mother. J Clin Med. 2020;9(5):1470

22. Park YB, Lee JW, Cho BS, et al. Incidence and etiology of overt gastrointestinal bleeding in adult patients with aplastic anemia. Dig Dis Sci. 2010;55:73-81.

23. Setzer ES, Webb IB, Wassenaar JW, Reeder JD, Mehta PS, Eitzman DV. Platelet dysfunction and coagulopathy in intraventricular hemorrhage in the premature infant. J Pediatr. 1982:100:599-605.

24. Duppre P, Sauer H, Giannopoulou EZ, et al. Cellular and hum-oral coagulation profiles and occurrence of IVH in VLBW and ELWB infants. Early Hum Dev. 2015;91:695-700.

25. Dohner ML, Wiedmeier SE, Stoddard RA, et al. Very high users of platelet transfusions in the neonatal intensive care unit. Transfusion. 2009;49:869-72.

\section{Publisher's Note}

Springer Nature remains neutral with regard to jurisdictional claims in published maps and institutional affiliations.
Ready to submit your research? Choose BMC and benefit from:

- fast, convenient online submission

- thorough peer review by experienced researchers in your field

- rapid publication on acceptance

- support for research data, including large and complex data types

- gold Open Access which fosters wider collaboration and increased citations

- maximum visibility for your research: over $100 \mathrm{M}$ website views per year

At BMC, research is always in progress.

Learn more biomedcentral.com/submissions 